\title{
Quality of Life in Behçet's Disease in Three Centers Experience
}

Enas S. Zahran', Sabry Shoeib ${ }^{1}$, Mona R. Waly*2, Nibal Mourad ${ }^{3}$, Emad M. El-Shebiny ${ }^{1}$

${ }^{1}$ Rheumatology and Immunology Unit, Department of Internal Medicine,

Faculty of Medicine, Menoufia University, Egypt.

${ }^{2}$ Department of Internal Medicine, Benha Teaching Hospital, the General Organization for

Teaching Hospitals and Institutes, Egypt.

${ }^{3}$ Rheumatology and Immunology Unit, Department of Internal Medicine,

Faculty of Medicine, Mansoura University, Egypt.

*Corresponding Author: Mona Refaat Mohamed Waly, Mobile: (+20)01229689584, E-Mail: tokayousef123@gmail.com

\begin{abstract}
Background: Behçet's syndrome (BS) is a systemic inflammatory vasculitis of unknown etiology, characinoid by recurrent oral, genital ulcers and uveitis. Its symptoms may affect patients' quality of life.

Objective: This study aimed to evaluate the quality of life (QoL) in patients with Behçet's disease (BD) in three centers experience (Menoufia University Hospital, Mansoura University Hospital, and Banha Teaching Hospital)

Patients and methods: A cross sectional study that was carried out on 70 BD patients selected from Rheumatology and Immunology Unit from Menoufia University Hospital, Benha Teaching Hospital, and Mansoura University Hospital from January 2019 till December 2020 on patients who were diagnosed by trained well qualified dermatologists and rheumatologist. All participants were assessed by the SF-36 QoL Scale to evaluate the QoL.

Results: The mean general health score was $12.0 \pm 2.09$. The mean limitations of activities score was $10.57 \pm 2.44$. The mean physical health problems score was $2.04 \pm 0.97$. The mean emotional health problems score was $1.53 \pm 0.90$. The mean social activities was $3.94 \pm 1.15$. The mean pain was $4.03 \pm 1.19$. The mean energy and emotions was 17.63 \pm 2.27 , and the mean overall QoL was $51.74 \pm 5.03$. Conclusion: QoL scores do not correlated with demographic characteristics such as age, gender, BMI and weight. We also found that disease characteristics such as presence of oral ulcer, genital ulcer, and arthritis and skin lesion do not affect QoL scores.
\end{abstract}

Keywords: Behçet's syndrome, quality of life.

\section{INTRODUCTION}

Rheumatologic diseases are common all around the world. Most rheumatologic diseases are chronic and result in loss of power. They could also be lifethreatening in certain cases ${ }^{(\mathbf{1})}$. The mortality rate of rheumatologic diseases in general population is $0.02 \%$. Behçet's disease is one of the rheumatologic diseases related to vasculitis ${ }^{(2)}$.

Behçet's disease (BD) is a chronic inflammatory disease that leads to recurrent aphthous ulcers of the mouth and genitalia, relapsing uveitis, and skin lesions such as erythema nodosum. Because BD is a chronic multisystem disorder, it may cause various problems in daily life or lead to functional disability ${ }^{(3)}$.

Behçet's disease is thought to be more common along the ancient Silk Road, extending from Asia to the Mediterranean. Estimates from Turkey vary from 80-370 cases per 100,000 populations, whereas prevalence estimates from Japan, Korea, China, and the Middle East vary from 13-20 cases per 100,000 populations ${ }^{(4)}$. Certain genetic and/or environmental factors play an important role in its development. The mean age at onset is between 20 and 30 . The disease is less prevalent in children and seniors ${ }^{(5)}$. Common symptoms of the disease include oral and genital ulcers, skin lesions and arthritis, which might be accompanied by ocular and vascular involvements ${ }^{(6)}$. These symptoms not only affect the physical and mental health of patients negatively, but they also diminish their quality of life (QoL) by causing several physical impairments ${ }^{(7)}$.
Chronic rheumatologic problems in patients with Behçet's disease are reported to limit their daily activities and have a negative impact on their self-esteem and relationships with others. It was also found that painful oral ulcers impede alimentation and speech as well as negatively affect the body image of the patients ${ }^{(6)}$. All these problems related to Behçet's disease negatively affect the biopsychological and social life of the patients and reduce their $\mathrm{QoL}^{(\mathbf{8})}$. QoL is a concept that encompasses being able to satisfy one's own basic needs, being satisfied with life, showing an adequate level of social interaction, allocating time to fun, feeling good emotionally and physically, being good at interpersonal relationships, having self-esteem as well as previous experiences ${ }^{(9)}$.

Evaluations of QoL could assist in developing care plans that ensure a better understanding of the behaviors and the psychological reactions of the patients as well as the difficulties they experience with adjusting to the disease and developing effective coping mechanisms ${ }^{(\mathbf{1 0})}$.

Complaints associated with Behçet's disease deteriorate the physical and mental health of the patients on the one hand, and reduces QoL by generating certain physical impairments on the other. It could be also said that assessing QoL in patients with Behçet's disease could also assist in developing more comprehensive nursing care plans. The importance of patients being evaluated by a holistic approach will be revealed. The parameters that may affect Behçet's disease patients' 
QoL focused on only one symptom. However, Behçet's disease may negatively affect patients physically, mentally and socially and may decrease their QoL significantly ${ }^{(7)}$. Aim of the study was to evaluate the quality of life (QoL) in patients with Behçet's disease in three centers experience (Menoufia University Hospital, Mansoura University Hospital, and Benha Teaching Hospital).

\section{PATIENTS AND METHODS}

This study was a cross sectional study that was carried out on 70 patients with Behçet's disease selected from Rheumatology and Immunology Unit from Menoufia University Hospital, Benha Teaching Hospital and Mansoura University Hospital from January 2019 till December 2020 on patients who were diagnosed by trained well qualified dermatologists and rheumatologist. All participants were assessed by the SF-36 QoL Scale to evaluate the QoL.

Inclusion criteria: patients with Behçet's disease according to international diagnostic criteria of Behçet's disease were included. Adult patients $>18$ years and less than 60 years of both sexes were enrolled in this study.

With vascular affection short form 36 (SF-36) physical component score (PCS) and mental component score (MCS) and Behçet's disease quality of life (BDQoL) questionnaires were filled by consecutive BS patients attending our outpatient clinic.

Exclusion criteria: pregnant women, malignancy and critically ill patients.

\section{Ethical approval:}

An approval of the study was obtained from Menoufia University academic and ethical committee. Every patient signed an informed written consent for acceptance of the operation.

This work has been carried out in accordance with The Code of Ethics of the World Medical Association (Declaration of Helsinki) for studies involving humans.

\section{Data Collection tools:}

Before starting to collect final data, a pilot study was carried out over 50 participants to fulfill the following purposes: Determination of the organization and administrative procedures. Testing the questionnaire form and detecting any modifications needed. Estimation of the time needed to collect the data and examination. Detection of the difficulties that might arise and how to deal with them.

\section{Data management:}

The data were coded, entered and analyzed by SPSS program (statistical package for the social sciences) version 14. Quantitative data were summarized as range, mean \pm Standard deviation $(\mathrm{SD})$, median and interquartile range (IQR). Qualitative data were summarized as number and percentage. $\mathrm{P} \leq 0.05$ was considered significant.

\section{RESULTS}

The demographic data of the studied cases are shown in table 1 .

Table (1): Distribution of the studied cases according to demographic data $(n=70)$

\begin{tabular}{|c|c|c|c|}
\hline & Demographic data & $\mathbf{N}$. & $\%$ \\
\hline \multirow{2}{*}{ Sex } & Male & 54 & 77.1 \\
\hline & Female & 16 & 22.9 \\
\hline \multirow{4}{*}{ Age (Years) } & $<20$ & 19 & 27.1 \\
\hline & $20-<30$ & 16 & 22.9 \\
\hline & $30-<40$ & 28 & 40 \\
\hline & $\geq 40$ & 7 & 10 \\
\hline \multirow{3}{*}{ Age (Years) } & Min. - Max. & \multirow{3}{*}{\multicolumn{2}{|c|}{$\begin{array}{c}8.50-45.0 \\
26.88 \pm 10.31 \\
28.50(19.0-35.0) \\
\end{array}$}} \\
\hline & Mean \pm SD & & \\
\hline & Median (IQR) & & \\
\hline \multirow{3}{*}{ Weight (kg) } & Min. - Max. & \multicolumn{2}{|c|}{$23.0-90.0$} \\
\hline & Mean \pm SD & \multicolumn{2}{|c|}{$66.26 \pm 13.61$} \\
\hline & Median (IQR) & \multicolumn{2}{|c|}{$68.0(61.0-76.0)$} \\
\hline \multirow{3}{*}{ Height (cm) } & Min. - Max. & \multicolumn{2}{|c|}{$147.0-190.0$} \\
\hline & Mean \pm SD & \multicolumn{2}{|c|}{$164.0 \pm 9.64$} \\
\hline & Median (IQR) & \multicolumn{2}{|c|}{$164.0(156.0-170.0)$} \\
\hline \multirow{3}{*}{ BMI $\left(\mathrm{kg} / \mathrm{m}^{2}\right)$} & Min. - Max. & \\
\hline & Mean \pm SD & \multirow{2}{*}{\multicolumn{2}{|c|}{$\begin{array}{c}24.46 \pm 3.96 \\
24.95(22.20-27.50)\end{array}$}} \\
\hline & Median (IQR) & & \\
\hline \multirow{2}{*}{ Smoking } & No & 53 & 75.7 \\
\hline & Heavy & 17 & 24.3 \\
\hline
\end{tabular}

The Clinical findings of the studied patients are shown in table 2 . 
Table (2): Clinical findings of the studied patients $(n=70)$

\begin{tabular}{|l|c|c|}
\hline \multicolumn{1}{|c|}{ Oral ulcer } & N. & $\%$ \\
\hline Oral ulcer & 19 & 27.1 \\
Mild & 12 & 17.1 \\
Moderate & 39 & 55.7 \\
Severe & & \\
Genital ulcer & 22 & 31.4 \\
No & 9 & 12.9 \\
Improved & 18 & 25.7 \\
Mild & 10 & 14.3 \\
Moderate & 11 & 15.7 \\
Severe & & \\
Eye & 28 & 40.0 \\
Anterior uveitis & 39 & 55.7 \\
Posterior uveitis & 8 & 11.4 \\
Retinal artery thrombosis & & \\
\hline Central nervous system Affection & 63 & 90 \\
No & 7 & 10.0 \\
Dural sinus thrombosis & & \\
\hline Patheragy & 70 & 100.0 \\
Negative & & 85.7 \\
\hline Arthritis & 60 & 14.3 \\
No & 10 & 88.6 \\
Unilateral ankle arthritis & 62 & 11.4 \\
\hline Stroke & 8 & 64.3 \\
No & 45 & 35.7 \\
Dural sinus thrombosis & 25 & \\
\hline Deep Venous Thrombosis & & \\
No & & \\
Yes & & \\
\hline \hline
\end{tabular}

There was no significant difference in the total QoL according to sex, age, oral ulcer, and genital ulcer (Table 3).

Table (3): Relation between total QoL and different parameters $(n=70)$

\begin{tabular}{|c|c|c|c|c|c|c|}
\hline & \multirow{2}{*}{$\mathbf{N}$} & \multicolumn{3}{|c|}{$\overline{\text { Total QoL }}$} & \multirow{2}{*}{ Test of Sig. } & \multirow{2}{*}{$\mathbf{p}$} \\
\hline & & Min. - Max. & Mean \pm SD. & Median & & \\
\hline \multicolumn{5}{|l|}{ Sex } & \multirow{3}{*}{$\begin{array}{c}\mathrm{U}= \\
4.150\end{array}$} & \multirow{3}{*}{0.883} \\
\hline Male & 54 & $36.0-62.0$ & $51.76 \pm 4.93$ & 52.0 & & \\
\hline Female & 16 & $44.0-63.0$ & $51.69 \pm 5.53$ & 52.50 & & \\
\hline \multicolumn{5}{|c|}{ Age (Years) } & \multirow{5}{*}{$\begin{array}{c}\mathrm{H}= \\
2.765\end{array}$} & \multirow{5}{*}{0.429} \\
\hline$<20$ & 19 & $46.0-55.0$ & $50.26 \pm 3.25$ & 50.0 & & \\
\hline $20-<30$ & 16 & $44.0-62.0$ & $52.0 \pm 4.93$ & 52.0 & & \\
\hline $30-<40$ & 28 & $44.0-63.0$ & $52.68 \pm 5.21$ & 52.50 & & \\
\hline$\geq 40$ & 7 & $36.0-59.0$ & $51.43 \pm 8.10$ & 53.0 & & \\
\hline \multicolumn{7}{|l|}{ Oral ulcer } \\
\hline Mild & 19 & $44.0-60.0$ & $52.21 \pm 4.34$ & 53.0 & \multirow{3}{*}{$\begin{array}{c}\mathrm{H}= \\
0.821\end{array}$} & \multirow{3}{*}{0.663} \\
\hline Moderate & 12 & $44.0-59.0$ & $50.75 \pm 4.79$ & 52.0 & & \\
\hline Severe & 39 & $36.0-63.0$ & $51.82 \pm 5.48$ & 52.0 & & \\
\hline \multicolumn{7}{|c|}{ Genital ulcer } \\
\hline $\mathrm{No}$ & 22 & $44.0-60.0$ & $51.45 \pm 4.35$ & 52.0 & \multirow{5}{*}{$\begin{array}{c}\mathrm{H}= \\
5.790\end{array}$} & \multirow{5}{*}{0.215} \\
\hline Improved & 9 & $46.0-59.0$ & $50.33 \pm 4.06$ & 49.0 & & \\
\hline Mild & 18 & $36.0-62.0$ & $53.61 \pm 6.30$ & 53.50 & & \\
\hline Moderate & 10 & $45.0-63.0$ & $52.20 \pm 5.27$ & 52.0 & & \\
\hline Severe & 11 & $44.0-56.0$ & $50.0 \pm 4.20$ & 50.0 & & \\
\hline
\end{tabular}

U: Mann Whitney test

$\mathrm{H}$ : $\mathrm{H}$ for Kruskal Wallis test

The grading of patients according to their general health is shown in table 4 . 
Table (4): Distribution of the studied cases according to general health $(n=70)$

\begin{tabular}{|c|l|c|c|c|c|c|c||}
\hline \multirow{2}{*}{$\mathbf{Q}$} & \multicolumn{1}{|c|}{ General Health } & \multicolumn{2}{|c|}{ Grade 1 } & \multicolumn{2}{c|}{ Grade 2 } & \multicolumn{2}{c|}{ Grade 3 } \\
\cline { 2 - 8 } & $\mathbf{N}$. & $\mathbf{\%}$ & $\mathbf{N}$. & $\mathbf{\%}$ & $\mathbf{N}$. & \% \\
\hline $\mathbf{1}$ & $\begin{array}{l}\text { In general, would you say your } \\
\text { health is? }\end{array}$ & 19 & 27.1 & 31 & 44.3 & 20 & 28.6 \\
\hline $\mathbf{2}$ & $\begin{array}{l}\text { Compared to one year ago, } \\
\text { how would you rate your } \\
\text { health in general now }\end{array}$ & 36 & 51.4 & 20 & 28.6 & 14 & 20.0 \\
\hline $\mathbf{3}$ & $\begin{array}{l}\text { I seem to get sick a little easier } \\
\text { than other people }\end{array}$ & 20 & 28.6 & 18 & 25.7 & 32 & 45.7 \\
\hline $\mathbf{4}$ & $\begin{array}{l}\text { I am as healthy as anybody I } \\
\text { know }\end{array}$ & 25 & 35.7 & 24 & 34.3 & 21 & 30.0 \\
\hline $\mathbf{5}$ & I expect my health to get worse & 21 & 30.0 & 26 & 37.1 & 23 & 32.9 \\
\hline $\mathbf{6}$ & My health is excellent & 18 & 25.7 & 23 & 32.9 & 29 & 41.4 \\
\hline
\end{tabular}

Grade 1: Excellent or Very good Grade 2: Good or Fair. $\quad$ Grade 3: Poor.

The descriptive data of the studied cases according to quality of life (SF-36) QOL scoring are shown in table 5.

Table (5): Descriptive analysis of the studied cases according to quality of life (SF-36) QOL scoring $(n=70)$

\begin{tabular}{||l|c|c|c|}
\hline \multicolumn{1}{|c|}{ Total Score } & Min. - Max. & Mean \pm SD. & Median (IQR) \\
\hline General Health & $8.0-17.0$ & $12.0 \pm 2.09$ & $12.0(10.0-13.0)$ \\
\hline Limitations of Activities & $5.0-15.0$ & $10.57 \pm 2.44$ & $11.0(9.0-13.0)$ \\
\hline $\begin{array}{l}\text { Physical Health } \\
\text { Problems }\end{array}$ & $0.0-4.0$ & $2.04 \pm 0.97$ & $2.0(1.0-3.0)$ \\
\hline $\begin{array}{l}\text { Emotional Health } \\
\text { Problems }\end{array}$ & $0.0-3.0$ & $1.53 \pm 0.90$ & $1.0(1.0-2.0)$ \\
\hline Social Activities & $2.0-6.0$ & $3.94 \pm 1.15$ & $4.0(3.0-5.0)$ \\
\hline Pain & $2.0-6.0$ & $4.03 \pm 1.19$ & $4.0(3.0-5.0)$ \\
\hline Energy and Emotions & $11.0-23.0$ & $17.63 \pm 2.27$ & $18.0(16.0-19.0)$ \\
\hline Overall QOL & $\mathbf{3 6 . 0}-\mathbf{6 3 . 0}$ & $\mathbf{5 1 . 7 4} \pm \mathbf{5 . 0 3}$ & $\mathbf{5 2 . 0}(\mathbf{4 9 . 0}-\mathbf{5 4 . 0})$ \\
\hline
\end{tabular}

\section{DISCUSSION}

Evaluations of QoL could assist in developing care plans that ensure a better understanding of the behaviors and the psychological reactions of the patients as well as the difficulties they experience with adjusting to the disease and developing effective coping mechanisms. Complaints associated with Behçet's disease deteriorate the physical and mental health of the patients on the one hand, and reduces QoL by generating certain physical impairments on the other ${ }^{(11)}$.

In this study we found that there were $54(77.1 \%)$ males and $16(22.9 \%)$ females. Nineteen patients (27.1\%) aged below 20, 16 (22.9\%) aged between 20 and 30, $28(40 \%)$ aged between 30-40 and $7(10 \%)$ aged above 40 . The mean age was $26.88 \pm 10.31$, the mean weight was $66.26 \pm 13.61$, the mean height was $164.0 \pm 9.64$, and the mean BMI was $24.46 \pm 3.96$. As for smoking there were $53(75.7 \%)$ with negative smoking and $17(24.3 \%)$ with heavy smoking.

Canpolat and Yurtsever ${ }^{(1)}$ found that number of male and female participants was the same 47 participants. Of all the participating patients $25.5 \%$ were between 20 and 30 years of age, while $32 \%$ were 42 or older. Bernabe et al. ${ }^{(12)}$ found that $85(24 \%)$ were male and $274(76 \%)$ were female while the mean of age $49.8( \pm 12.4)$ of 359 had a confirmed diagnosis of BS. Bodur et al. ${ }^{(13)}$ found that Forty-one BD patients (22 men and 19 women) with a mean age of $33.3 \pm 9.3$ years were included to the study

In this study we demonstrated that there were 19 $(27.1 \%)$ with mild oral ulcer, $12(17.1 \%)$ with moderate oral ulcer and $39(55.7 \%)$ with severe oral ulcer. As for genital ulcer there were 9 (12.9\%) with improved genital ulcer, 18 (25.7\%) with mild genital ulcer, $10(14.3 \%)$ with moderate genital ulcer and 11 $(15.7 \%)$ with severe genital ulcer. As for eye there were $28(40 \%)$ with anterior uveitis, 39 (55.7\%) with posterior uveitis and $8(11.4 \%)$ with retinal artery thrombosis. As for CNS affection there were 63 $(90 \%)$ with negative affection and $7(10 \%)$ with dural sinus thrombosis. All patients had negative pathergy, as for arthritis there was $60(85.7 \%)$ with negative arthritis and $10(14.3 \%)$ with unilateral ankle arthritis. As for stroke there were $62(88.6 \%)$ with negative stroke and $8(11.4 \%)$ with dural sinus thrombosis. There were 25 (35.7\%) had deep venous thrombosis (DVT).

Canpolat and Yurtsever ${ }^{(1)}$ found that in study on 94 participants had a confirmed diagnosis of BS, 
there were $76(80.9 \%)$ had oral ulcer, $31(33 \%)$ had genital ulcer, $29(30.9 \%)$ had eye involvement, 31 (33\%) had arthritis, $50(53.2 \%)$ had skin lesions and $15(16 \%)$ had vascular involvements. Fabiani et al. (14) found that in study to evaluate quality of life impairment in Bechet's disease and relationship with disease activity according to BD organ involvement; mucosal 37 (100\%), eye 21 (56.8\%), skin 22 (59.5\%), articular (arthralgia/arthritis) 32 (18/14) (86.5\%), myalgia 17 (45.9\%), CNS 13 (35.1\%), gut $13(13.5 \%)$ and vessels $5(13.5 \%)$.

In this study we found that according to general health there were $19(27.1 \%)$ with grade $1,31(44.3 \%)$ with grade 2, $20(28.6 \%)$ with grade 3 , according to moderate activities there were $24(34.3 \%)$ with not limited activity, 16 (22.9\%) with little limited activity, $30(42.9 \%)$ with limited a lot activity, according to cut down amount of time patients spend on work or another activities there were 37 (52.9\%), according to not doing work or other activities as carefully as usual there were $35(50 \%)$. according to bodily pain patients had during the past 4 weeks there were 23 (32.9\%) with mild pain, 24 (34.3\%) with moderate pain, 23 $(32.9 \%)$ with severe pain, according to having a lot of energy there were $18(25.7 \%)$ all time, $31(44.3 \%)$ some time, 21 (30\%) with none of time.

Canpolat and Yurtsever ${ }^{(1)}$ found that according to experiencing pain there were $71(75.5 \%)$, according to bodily pains affected daily living 54 (59.6\%) were affected, according to experiencing pain \pm sleep problems there were $30(31.9 \%)$, according to sleep problems affected daily living 29 (30.9\%) were Affected, according to experiencing fatigue 72 (76.6\%), according to fatigue affected daily living 65 (69.1) were affected and according to social relationship affected by the disease 22 (23.4\%) were affected.

An increase in the pain-related symptoms leads to negative emotional and cognitive processes and stimulates feelings of pessimism, sadness and desperation. Bodily pain might cause depression, and patients might reject treatment as a result. Bodily pain might also cause anxiety, fear, loss of concentration and loss of control. Emotional well-being, sexual function, physical appearance and social relationships might get damaged ${ }^{(15)}$.

In this study we cleared that the mean general health $12.0( \pm 2.09 \mathrm{SD})$ with range (8-17), the mean limitations of activities 10.57 ( \pm 2.44 SD) with range (5-15), the mean physical health problems $2.04( \pm$ $0.97 \mathrm{SD}$ ) with range (0-4), the mean emotional health problems $1.53( \pm 0.90 \mathrm{SD})$ with range (0-3), the mean social activities 3.94 ( $\pm 1.15 \mathrm{SD})$ with range (2-6), the mean pain $4.03( \pm 1.19 \mathrm{SD})$ with range $(2-6)$, the mean energy and emotions $17.63( \pm 2.27 \mathrm{SD})$ with range (11-23), the mean overall QOL $51.74( \pm 5.03$ SD) with range (36-63).

Canpolat and Yurtsever (1) found that the patients' QoL scores were low. The means and standard deviations for the SF-36 QoL subscales were calculated as follows: physical functioning (63.82 \pm 23.23), social functioning (66.19 \pm 26.31$)$, rolephysical $(32.97 \pm 42.63)$, role-emotional $(33.33 \pm$ 40.60), mental health $(51.65 \pm 13.76)$, vitality $(35.15$ $\pm 21.21)$, bodily pain $(51.18 \pm 24.93)$ and general health $(44.29 \pm 21.47)$. Fabiani et al. ${ }^{(14)}$ found that mean \pm SD values of SF-36 QoL subscales obtained in patients were physical functioning $71.73 \pm 27.75$, role-physical $50.96 \pm 42.86$, bodily pain $49.98 \pm$ 25.43 , general health $44.17 \pm 21.30$, vitality $50 \pm 22.7$, social functioning $63.52 \pm 28.04$, role-emotional $62.02 \pm 41.25$ and mental health $62.30 \pm 19.93$.

In the study in our hands we found that there is no significant difference in total QoL as regards sex, age, oral ulcer and genital ulcer. Similarly Melikoğlu $\boldsymbol{e t}$ al. (16) found that gender was not associated with statistical differences when compared HAQ and SF36 scores. In contrast Fabiani et al. ${ }^{(14)}$ found that gender distinctions show a different impact on patients QoL as many SF-36 sub scores are significantly reduced in female compared to male patients. Canpolat and Yurtsever ${ }^{(1)}$ observed that oral ulcers negatively affect QoL subscales and found that genital ulcers negatively affect QoL subscales. Mumcu et al. ${ }^{\left({ }^{17)}\right.}$ found that patients with oral ulcers had lower mean scores on physical functioning, rolephysical, bodily pain and general health compared to healthy individuals. In the same study, it was concluded that the patients with an active Behçet's disease had lower mean scores on physical functioning, role-emotional, vitality compared to those who did not have the disease actively. Bodur $\boldsymbol{e t}$ al. ${ }^{(13)}$ found that mean scores on physical and psychosocial categories were lower for the patients with oral ulcers. The results of the present study are in line with the results of these studies.

In this study we demonstrated that there was no significant difference in total QoL as regards CNS affected, pathergy, arthritis, smoking, stroke and DVT. Bodur et al. ${ }^{(13)}$ found that patient's painful joints are significantly associated with impaired QoL. Fabiani et al. ${ }^{(14)}$ found that no difference in QoL evaluation is observed according to the presence and absence of eye or nervous manifestations in patients with ocular and CNS involvement.

Our results showed that there was no significant difference between total QOL and age. Fabiani $\boldsymbol{e t}$ al. (14) found that demographic characteristics, such as age, do not correlated to QoL Canpolat and Yurtsever (1) found that the patients' sociodemographic characteristics such as age, gender, education level and work status affect QoL scores in which patients between 31 and 41 years of age had lower mean scores especially on social functioning and general health. Patients who received their diagnosis in the third decade were mostly in their late twenties or early thirties at the time they received a diagnosis. People around these ages have to assume a 
lot of responsibilities both in their families and in the work place. These patients have to cope with the problems associated with Bechet's disease while they are struggling to fulfill their responsibilities at home and in the workplace. It is thought that QoL diminishes as the patients are going through such stressful periods.

\section{CONCLUSION}

In this study, we conclude that QoL scores in patients with BD does not correlated with demographic characteristics such as age, gender, BMI and Weight. We also found that disease characteristics such as presence of oral ulcer, genital ulcer, and arthritis and skin lesion do not affect QoL scores. We recommend further studies on large number of BD patients.

\section{REFERENCES}

1. Canpolat Ö, Yurtsever S (2011): The quality of life in patients with Behçet's disease. Asian Nursing Research, 5(4): 229-235.

2. West $\mathbf{S}$ (2000): Excerpts from secrets of rheumatology. Trans. Olia MB, Soleimani H. Yazd: Publication of Yazd, 16(33):125-150.

3. Nair J, Moots R (2017): Behcet's disease. Clinical Medicine, 17(1): 71.

4. El Jammal T, Loria O, Jamilloux Y et al. (2021): Uveitis as an open window to systemic inflammatory diseases. Journal of Clinical Medicine, 10(2): 281-5.

5. Atmaca S, Sönmez A (2004): Ocular involvement in Behçet Disease patients. Retina Vitreus, 12: 77-86.

6. Gilworth G, Chamberlain A, Bhakta B et al. (2004): Development of the BD-QoL: A quality of life measure specific to Behçet's disease. The Journal of Rheumatology, 31: 931-936.

7. Uguz F, Dursun R, Kaya $\mathbf{N}$ et al. (2006): Emotional symptoms and quality of life in Behçet Disease patients. Journal of Anatolian Psychiatry, 7: 133-139.
8. Tanriverdi N, Taşkıntuna I, Duru C et al. (2003): Health-related quality of life in Behçet patients with ocular involvement. Japanase Journal of Ophtalmology, 47: 85-92.

9. Ertam I, Kitapcioğlu G, Aksu K et al. (2009): Quality of life and its relation with disease severity in Behçet's disease Clinical Experimental Rheumatology, 27: 1822.

10. Acaray A, Pinar R (2004): Evaluation of chronic heamodialysis patients QOL. Journal of Cumhuriyet University Nursing High School, 8: 1-11.

11. Thieme A, Belgrave D, Doherty G (2020): Machine learning in mental health: A systematic review of the HCI literature to support the development of effective and implementable ML systems. ACM Trans Comput Hum Interact, 20: 27-32.

12. Bernabe E, Marcenes $W$, Mather $J$ et al. (2010): Impact of Behçet's syndrome on health-related quality of life: influence of the type and number of symptoms. Rheumatology, 49(11): 2165-2171.

13. Bodur H, Borman P, Özdemir Y et al. (2006): Quality of life and life satisfaction in patients with Behçet's disease: Relationship with disease activity. Clinical Rheumatology, 25: 229-333.

14. Fabiani C, Vitale A, Emmi G et al. (2017): Efficacy and safety of adalimumab in Behçet's disease-related uveitis: a multicenter retrospective observational study. Clinical Rheumatology, 36(1): 183-189.

15. Thorn B (2017): Cognitive therapy for chronic pain: a step-by-step guide. Guilford Publications, 71(3): 248252.

16. Melikoğlu M, Melikoglu M (2014): What affects the quality of life in patients with Behcet's disease. Acta Reumatol Port., 39, 46-53.

17. Mumcu G, Niazi S, Stewart J et al. (2009): Oral health and related quality of life status in patients from UK and Turkey: a comparative study in Behcet's disease. Journal of Oral Pathology \& Medicine, 38(5): 406-409. 